\title{
Kindergarteners' Exposure to Passive Smoking at Home in Japan and China
}

\author{
Harumi Bando, ${ }^{1,2}$ and Tohru Yoshida ${ }^{2}$
}

\begin{abstract}
Background : This study aimed to clarify the characteristics and actual conditions in the home environments of children who are exposed to passive smoking in China and Japan. Methods : Participants included 3- to 5-year-old kindergarteners (including children attending nursery schools) who lived in Osaka, Japan (975 children) and Beijing, China (1,021 children). We conducted a questionnaire survey of their guardians. Results : The questionnaires were collected from 583 households (59.8\%) in Japan and 632 households (61.9\%) in China. There were at-home smokers in 323 households (55.4\%) in Japan and 318 households (50.3\%) in China. Passive smoking by children at home was observed in 106 households (18.2\%) in Japan and 97 households (15.3\%) in China. Conclusions : The results of this survey suggest that a common factor to both countries was that the "number of cigarettes consumed per day" is correlated with an increase in the percentage of children who are exposed to passive smoking. Moreover, the findings suggest that the "number of at-home smokers" in Japan and "children aged 5 years old or older" in China increase the percentage of children who are exposed to passive smoking. (Kitakanto Med J $2011 ; 61: 25 \sim 30$ )
\end{abstract}

Key words : Passive Smoking, Kindergartener, China, Japan

\section{Introduction}

According to the "2009 Japan Smoking Rate Survey", the average smoking rate among Japanese adult males is $38.9 \%$ and the average smoking rate among Japanese adult females is $11.9 \%$. Furthermore, according to the WHO's regional smokingrelated statistics, the smoking rate in China is $66.9 \%$ among males and 4.2\% among females. ${ }^{2}$ In Japan, the total sale of paper-wrapped cigarettes ${ }^{1}$ was 312.6 billion in 2002 (reaching a peak in 1997 and gradually decreasing thereafter); this was twice the amount of sales in 1965, making Japan the third largest consumer nation of paper-wrapped cigarettes in the world. In China, the total sale of paper-wrapped cigarettes was 1.643 trillion, making China the largest consumer nation in the world. ${ }^{2}$ Based on these statistics, the Japanese consume twice as many cigarettes as the world average and Chinese consumers account for one-third of the world's smoking population. There is obvious concern regarding the health effects of smoking in both countries. Moreover, since both countries have high smoking rates and high levels of cigarette consumption, the smoking environment has raised concern regarding the effects on children's health.

Some reports indicate that passive smoking causes asthma, ${ }^{3}$ otitis media, ${ }^{4}$ sudden infant death syndrome (SIDS), ${ }^{5}$ and other conditions in children. It is believed that background factors related to such physical effects include the child's specific physical characteristics and the characteristics of the environment. It is thought that infants are significantly affected by indoor environments because they spend most of their time indoors and they are more susceptible to volatile substances at floor level because their growth and developmental tasks occur in this low position. ${ }^{6}$ Infants also engage in mouthing (action of placing a variety of surrounding items into their mouth) during their growing phase and they may be orally exposed to substances on any surface or object that they can reach. ${ }^{6}$ In addition, the excretory function of infants is not fully developed as a physical function. Under such conditions, their exposure to passive smoking is

1 Community Health Nursing, Nara Medical University School of Nursing, 840 Shijyo-cho, Kashihara, Nara 634-8521, Japan

2 School of Health Sciences, Gunma University Faculty of Medicine, 3-39-22 Showa-machi, Maebashi, Gunma 371-8511, Japan Received: November 18, 2010

Address: HARUMI BANDO Community Health Nursing, Nara Medical University School of Nursing 840 Shijyo-cho, Kashihara, Nara 634-8521, Japan 
different from the exposure of adults. Furthermore, the International Union Against Cancer warns that children spend most of their time indoors and that the main location where they are exposed to passive smoking is in the home. ${ }^{7}$

Based on these factors, it is believed that passive smoking in the home may affect children's health, and given the smoking environments in Japan and China, there is concern regarding the health conditions of home environments of children.

This study aimed to clarify the characteristics of passive smoking and the actual conditions in the home environments of children in China and Japan in order to prevent the health effects of smoking for the next generation.

\section{Participants and Methods}

\section{Participants}

The participants included 3- to 5-year-old kindergarteners (including children attending nursery schools) who were born between 2000 and 2002 and lived in Osaka, Japan (975 children) or Beijing, China, (1,021 children).

\section{Survey method}

We distributed and collected a self-administered questionnaire to the children's guardians between July 1 and October 15, 2006.

\section{Major survey questions}

The major survey questions included : the ages of the mother and father; whether there were other family members living in the home; whether there were any at-home smokers; whether passive smoking occurred in the home; and the number of cigarettes consumed per day.

\section{Method of analysis}

The relationship between passive smoking at home and the above questions and other variables related to the children were examined by chi-square test.

Furthermore, multiple logistic regression analysis was performed using the forced entry method; passive smoking at home was used as the dependent variable. Questions and variables, which became significant by chi-square test during the investigation, were used as the independent variables.

\section{Ethical considerations}

The questionnaire included an explanation about the purpose of the survey and reassurance that participation was voluntary and that all personal information would be protected. Returning the questionnaire was considered to constitute informed consent.

\section{Results}

\section{Collection rates}

The questionnaires were collected from 591 people (60.6\%) in Japan and 656 people (64.3\%) in China. The response rate was 583 people $(59.8 \%)$ in Japan and 632 people $(61.9 \%)$ in China.

\section{Gender and age of children}

The children included 297 males (50.9\%) and 286 females (49.1\%) in Japan and 358 males (56.6\%) and 274 females $(43.4 \%)$ in China.

\section{Age of parents}

In Japan, the average age of the mothers was $33.9 \pm 4.3$ years; ages ranged from 21 to 46 years old. In China, the average age of the mothers was $32.9 \pm 3.7$ years; ages ranged from 22 to 49 years old. In Japan, the average age of the fathers was $35.6 \pm 5.1$ years ; ages ranged from 23 to 65 years old. In China, the average age of the fathers was $35.4 \pm 4.5$ years; ages ranged from 26 to 59 years old.

\section{Family members other than parents living in the home}

The number of family members, other than the parents, living in the home was 109 persons (18.7\%) in Japan and 99 persons (15.7\%) in China.

\section{Conditions related to smokers}

There were 96 smoking mothers (16.5\%) in Japan and 6 smoking mothers $(0.9 \%)$ in China, and the smoking rate was higher among Japanese mothers. There were 283 smoking fathers $(48.5 \%)$ in Japan and 305 smoking fathers $(48.3 \%)$ in China. The number of at-home smokers, including parents and other family members living in the home, was 323 persons $(55.4 \%)$ in Japan and 318 persons $(50.3 \%)$ in China.

\section{Smoking in the presence of children}

There were 29 mothers $(5.0 \%)$ in Japan and 2 mothers $(0.3 \%)$ in China who smoked in the presence of their children. There were 87 fathers (14.9\%) in Japan and 90 fathers (14.2\%) in China who smoked in the presence of their children. There were 106 athome smokers (18.2\%) in Japan and 97 home smokers $(15.3 \%)$ in China who smoked in the presence of their children, including parents and other family members living in the home (Table 1, 2, 3).

\section{Number of cigarettes consumed per day for smokers}

The average number of cigarettes consumed per 
Table 1 Conditions related to smokers

\begin{tabular}{|c|c|c|c|c|}
\hline \multirow{2}{*}{ Variables } & \multicolumn{2}{|c|}{ Japan $(\mathrm{n}=583)$} & \multicolumn{2}{|c|}{ China $(n=632)$} \\
\hline & $\mathrm{n}$ & $\%$ & $\mathrm{n}$ & $\%$ \\
\hline \multicolumn{5}{|l|}{ Smoker } \\
\hline Mothers & 96 & 16.5 & 6 & 0.9 \\
\hline Fathers & 283 & 48.5 & 305 & 48.3 \\
\hline Family members & 44 & 7.5 & 26 & 4.1 \\
\hline At-home smokers & 323 & 55.4 & 318 & 50.3 \\
\hline \multicolumn{5}{|c|}{ Smoking in the presence of children } \\
\hline Mothers & 29 & 5.0 & 2 & 0.3 \\
\hline Fathers & 87 & 14.9 & 90 & 14.2 \\
\hline Family members & 17 & 2.9 & 7 & 1.1 \\
\hline At-home smokers & 106 & 18.2 & 97 & 15.3 \\
\hline
\end{tabular}

Table 2 Smoking in the presence of children (Japan)

$(n=583)$

\begin{tabular}{|c|c|c|c|c|}
\hline \multirow[t]{2}{*}{ Age of the children } & \multicolumn{2}{|c|}{$\begin{array}{l}\text { Smoking in the } \\
\text { presence of children } \\
\text { Yes }(n=106)\end{array}$} & \multicolumn{2}{|c|}{$\begin{array}{l}\text { Smoking in the } \\
\text { presence of children } \\
\text { No }(n=477)\end{array}$} \\
\hline & $\mathrm{n}$ & $\%$ & $\mathrm{n}$ & $\%$ \\
\hline 3 years & 8 & 10.7 & 67 & 89.3 \\
\hline 4 years & 52 & 20.3 & 204 & 79.7 \\
\hline 5 years & 46 & 18.3 & 206 & 81.7 \\
\hline
\end{tabular}

Table 3 Smoking in the presence of children (China)

$(n=632)$

\begin{tabular}{|c|c|c|c|c|}
\hline \multirow[t]{2}{*}{ Age of the children } & \multicolumn{2}{|c|}{$\begin{array}{l}\text { Smoking in the } \\
\text { presence of children } \\
\text { Yes }(n=97)\end{array}$} & \multicolumn{2}{|c|}{$\begin{array}{l}\text { Smoking in the } \\
\text { presence of children } \\
\text { No }(n=535)\end{array}$} \\
\hline & $\mathrm{n}$ & $\%$ & $\mathrm{n}$ & $\%$ \\
\hline 3 years & 2 & 4.2 & 46 & 95.8 \\
\hline 4 years & 27 & 11.0 & 218 & 89.0 \\
\hline 5 years & 68 & 20.1 & 271 & 79.9 \\
\hline
\end{tabular}

day by the at-home smokers was 17.0 (SD : 8.6), ranging from 1 to 60 , in Japan, and in China the average number of cigarettes consumed per day was 10.1 (SD : 6.9), ranging from 1 to 40.

\section{Number of at-home smokers}

The number of at-home smokers was 1.7 (SD : 0.9 ), ranging from 1 to 5 , in Japan, and 1.1 (SD : 0.4), ranging from 1 to 3 , in China.

\section{Smokers smoking in the presence of children and related factors}

Factors for which there was a significant association with passive smoking status in Japan included "number of at-home smokers" ( $p<0.01)$, and "number of cigarettes consumed per day" $(p<0.05)$.

Factors for which there was a significant association with passive smoking status in China included "number of cigarettes consumed per day" $(p<0.01)$, and "children aged 5 years old or older" $(p<0.01)$.

The results of the multiple logistic regression analysis indicated that, concerning the "number of cigarettes consumed per day", 10 or over compared to
9 or less had a higher odds ratio (OR 2.57, 95\% CI $1.02-6.51, p<0.05)$ and, concerning the "number of at-home smokers", 2 and over compared to 1 had a higher odds ratio (OR 2.04, 95\% CI 1.21-3.46, $p<0.01$ ) in Japan. In China, concerning the "number of cigarettes consumed per day", 10 or over compared to 9 or less had a higher odds ratio (OR 4.94, 95\% CI 2.73$8.73, p<0.01)$ and children aged 5 years or older compared to 4 years and younger had a higher odds ratio (OR 2.44, 95\% CI 1.43-4.18, $p<0.05$ ) (Table 4, 5, $6,7)$.

\section{Discussion}

\section{Age of children}

We found that the passive smoking rate increased among older children. This suggests the possibility that as the children become older, less attention is paid to the passive smoke received by children. Our results show that the passive smoking rate increased when the children became 5 years old ; therefore, we recommend that parents must be educated to pay attention to the issue of passive smoking before their children reach 5 years old. 
Table 4 Smoking in the presence of children and related factors (Japan) $(n=276)$

\begin{tabular}{|c|c|c|c|c|c|c|}
\hline \multirow[t]{2}{*}{ Variables } & \multicolumn{2}{|c|}{$\begin{array}{l}\text { Smoking in the } \\
\text { presence of children } \\
\text { Yes }(n=95)\end{array}$} & \multicolumn{2}{|c|}{$\begin{array}{l}\text { Smoking in the } \\
\text { presence of children } \\
\text { No }(n=181)\end{array}$} & \multirow[t]{2}{*}{$\begin{array}{c}\chi^{2} \\
\text { Value }\end{array}$} & \multirow[t]{2}{*}{$\begin{array}{c}\mathrm{P} \\
\text { Value }\end{array}$} \\
\hline & $\mathrm{n}$ & $\%$ & $\mathrm{n}$ & $\%$ & & \\
\hline \multicolumn{7}{|l|}{ Children age } \\
\hline 4 years or younger & 57 & 60.0 & 100 & 55.2 & 0.573 & 0.449 \\
\hline 5 years or over & 38 & 40.0 & 81 & 44.8 & & \\
\hline \multicolumn{7}{|l|}{ Gender of children } \\
\hline male & 46 & 48.4 & 99 & 54.7 & 0.984 & 0.321 \\
\hline female & 49 & 51.6 & 82 & 45.3 & & \\
\hline \multicolumn{7}{|c|}{ Number of cigarettes consumed per day } \\
\hline 9 or less & 6 & 6.3 & 28 & 15.5 & 4.833 & $0.028^{*}$ \\
\hline 10 or over & 89 & 93.7 & 153 & 84.5 & & \\
\hline \multicolumn{7}{|l|}{ At-home smokers } \\
\hline 1 & 54 & 56.8 & 133 & 73.5 & 7.894 & $0.005^{* *}$ \\
\hline 2 or over & 41 & 43.2 & 48 & 26.5 & & \\
\hline
\end{tabular}

Table 5 Smoking in the presence of children and related factors (China)

$(n=309)$

\begin{tabular}{|c|c|c|c|c|c|c|}
\hline \multirow[t]{2}{*}{ Variables } & \multicolumn{2}{|c|}{$\begin{array}{l}\text { Smoking in the } \\
\text { presence of children } \\
\text { Yes }(n=100)\end{array}$} & \multicolumn{2}{|c|}{$\begin{array}{l}\text { Smoking in the } \\
\text { presence of children } \\
\text { No }(n=209)\end{array}$} & \multirow[t]{2}{*}{$\begin{array}{c}\chi^{2} \\
\text { Value }\end{array}$} & \multirow[t]{2}{*}{$\begin{array}{c}\mathrm{P} \\
\text { Value }\end{array}$} \\
\hline & $\mathrm{n}$ & $\%$ & $\mathrm{n}$ & $\%$ & & \\
\hline \multicolumn{7}{|l|}{ Children age } \\
\hline 4 years or younger & 29 & 29.0 & 107 & 51.2 & 13.253 & $0.000 * *$ \\
\hline 5 years or over & 71 & 71.0 & 102 & 48.8 & & \\
\hline \multicolumn{7}{|l|}{ Gender of children } \\
\hline male & 63 & 63.0 & 119 & 56.9 & 1.027 & 0.311 \\
\hline female & 37 & 37.0 & 90 & 43.1 & & \\
\hline \multicolumn{7}{|c|}{ Number of cigarettes consumed per day } \\
\hline 9 or less & 20 & 20.0 & 117 & 56.0 & 35.481 & $0.000 * *$ \\
\hline 10 or over & 80 & 80.0 & 92 & 44.0 & & \\
\hline \multicolumn{7}{|l|}{ At-home smokers } \\
\hline 1 & 91 & 91.0 & 188 & 90.0 & 0.085 & 0.771 \\
\hline 2 or over & 9 & 9.0 & 21 & 10.0 & & \\
\hline
\end{tabular}

Table 6 Multiple logistic regression analysis using smoking in the presence of children as the dependent variable (Japan)

\begin{tabular}{ccc}
\hline \multicolumn{1}{c}{ Variables } & Odds ratio & $95 \%$ CI \\
\hline $\begin{array}{c}\text { Number of cigarettes consumed per day } \\
9 \text { or less }{ }^{\dagger}\end{array}$ & 1 & $1.02-6.51$ \\
10 or over & 2.57 & 1 \\
At-home smokers $^{\dagger}$ & 2.04 & $1.21-3.46$ \\
2 and over & & $\dagger:$ control group
\end{tabular}

Table 7 Multiple logistic regression analysis using smoking in the presence of children as the dependent variable (China)

\begin{tabular}{lcc}
\hline \multicolumn{1}{c}{ Variables } & Odds ratio & $95 \%$ CI \\
\hline $\begin{array}{c}\text { Number of cigarettes consumed per day } \\
9 \text { or less }{ }^{\dagger} \\
10 \text { or over }\end{array}$ & 1 & $2.73-8.73$ \\
Children's age & & 1 \\
5 years or younger ${ }^{\dagger}$ & 2.44 & $1.43-4.18$ \\
5 years or over & & $\dagger:$ control group
\end{tabular}


Furthermore, this survey targeted 3- to 5-year-old children, but there is a possibility that the passive smoking rate continues to increase as the children become older ; therefore, guardians with children aged 5 years old or older must pay continuous attention to the issue of passive smoking.

\section{Number of cigarettes consumed per day}

The rate of smoking in the presence of children increased as the number of cigarettes consumed per day increased. Reports indicated that a higher number of cigarettes consumed per day is associated with a greater dependency on smoking. ${ }^{8}$ It is likely that a greater dependency on smoking leads not only to problems for the smokers themselves but also to a higher rate of passive smoking for their children.

Furthermore, while not all cigarette smoking necessarily leads to passive smoking, it is likely that as more cigarettes are consumed, the number of times and opportunities for passive smoking to occur increases. Based on this, it would be logical to assume that providing heavy smokers with support for quitting smoking would eventually result in preventing children from exposure to passive smoke.

\section{Number of at-home smokers}

As the number of at-home smokers increased, the rate of smokers who smoked in the presence of their children increased. Based on this finding, parents and the entire household must be educated to pay attention to the issue of passive smoking. Furthermore, it is probable that having many smokers in the household makes smoking behavior very familiar for children and creates an environment that facilitates children's ready acceptance of smoking behavior. It is said that smoking behavior among family members creates smokers in the next generation ${ }^{9}$; therefore, it is important to provide support for smoking cessation for individuals, families, and entire households in order to break this generational chain.

This survey did not reveal any significant relationship with the number of at-home smokers in China, but it is possible that there are more opportunities in China to be exposed to passive smoking in places other than the home compared to Japan because there is a Chinese cultural practice known as "Xi Yan" of offering cigarettes to others on the Lunar New Year and other celebrations.

\section{Family relationships and passive smoking}

This survey indicated that it was most often the father who exposed their children to passive smoking; therefore, it is necessary to focus on fathers when raising awareness of the issue of passive smoking.
Furthermore, this survey indicated a lower rate of mothers exposing their children to passive smoking. However, Ino, et al. (2006) found that the nicotine levels measured in children were mostly due to passive smoking caused by the mothers. ${ }^{10}$ This is because children spend most of their time indoors and have frequent contact with their mothers. This information can be incorporated into educational programs that target mothers.

\section{Limitations of this study}

The collection rate of questionnaires in both countries was approximately $60 \%$. Consequently, it may be difficult to say that this survey actually reflects the conditions of passive smoking for infants and children.

Furthermore, we defined smoking in the presence of children as passive smoking in this survey, but currently, some reports have indicated the possibility of passive smoking in places without the presence of children, ${ }^{11}$ and such cases of passive smoking were not included in the results.

Moreover, based on recent social trends, it is believed that people may feel some reluctance or resistance to answering questions about passive smoking and smoking habits. Therefore, we may not have collected accurate answers from all of our participants. We believe that one useful measure would be to conduct a study with additional information obtained by measuring exposure to passive smoking.

\section{Conclusion}

This survey suggests that a factor common to both countries, is that an increase in the "number of cigarettes consumed per day" is correlated with an increase in the rate of passive smoking among children. Moreover, the results suggest that there is an increased the rate of passive smoking among children with the "number of at-home smokers" in Japan and for "children aged 5 years old or older" in China. We recommend that action and interventions to prevent passive smoking should consider these characteristics.

\section{Acknowledgements}

We would like to thank Song $\mathbf{J}$ at the Chinese Nursing Association Beijing China; Ogata Akira, professor emeritus at the Fukui Medical University; the guardians of the kindergarteners; the kindergarten staff ; and nurses in China and Japan for their cooperation and understanding in conducting this survey.

This study was conducted with financial assistance from the Japan China Medical Association and presented at The First Asia Pacific Conference on Health Promotion and Education. 


\section{References}

1. Japan Tobacco Incorporated. Japan Smoking Rate Survey 2005.

2. Mackay J, Michael E, Omar S, et al. The Tobacco ATLAS 2003.

3. Hiroshi Odajima. Asthma and passive smoking. The Journal of the Japan Pediatric Society 2008 ; 49 : 10. 12991308.

4. Yílmaz G, Hízlí S, Karacan C, et al. Effect of passive smoking on growth and infection rates of breast-fed and non-breast-fed infants. Pediatr Int 2009; 51: 352-358.

5. Blair PS, Fleming PJ, Bensley D, et al. Smoking and the sudden infant death syndrome: results from 1993-5 casecontrol study for confidential inquiry into stillbirths and deaths in infancy. BMJ 1996; 313 : 195-198.

6. Environmental Health Department, Ministry of the Environment. Report of the Committee on the Children's
Environmental Health 2006.

7. UICC. Protecting our children from second-hand smoke 2008.

8. Vink JM, Willemsen G, Beem AL, et al. The Fagerström Test for Nicotine Dependence in a Dutch sample of daily smokers and ex-smokers. Addict Behav 2005; 30 : 575579.

9. Osaki Y. Adolescent Smoking Behavior, Associated Environmental Factors, and Countermeasures. J. Natl. Inst. Public Health 2005; 54 : 284-289.

10. Ino T, Shibuya $T$, Saito K, et al. Investigation of Actual Status for Children with Passive Smoking and Impact on Motivation for Smoking Cessation by Smoking Screening Program. The Journal of the Japan Pediatric Society 2006; 110: 1105-1111.

11. Winickoff JP, Friebely J, Susanne E, et al. Beliefs about the health effects of "thirdhand" smoke and home smoking bans. Pediatrics 2009; 123: 74-79. 